\title{
Impairment of executive functions in patients with Generalized Anxiety Disorder
}

\author{
Prejuízo das funções executivas em pacientes com transtorno de ansiedade generalizada \\ Deterioro de las funciones ejecutivas en pacientes con trastorno de ansiedad generalizada
}

Received: 01/11/2022 | Reviewed: 01/15/2022 | Accept: 01/17/2022 | Published: 01/19/2022

\author{
Gabrieli Camossa Armagni \\ ORCID: https://orcid.org/0000-0001-9941-5852 \\ Federal University of São Paulo, Brazil \\ E-mail: gabriellicamossa@gmail.com \\ Gabriel Fernandes Klaus \\ ORCID: https://orcid.org/0000-0003-2602-4759 \\ Regional Hospital of Mato Grosso do Sul, Brazil \\ E-mail: gfklaus@gmail.com \\ Maria Beatriz Souza Cardoso \\ ORCID: https://orcid.org/0000-0002-1437-9432 \\ University of West Paulista, Brazil \\ E-mail: souzab629@gmail.com \\ Samuel Augusto Ferreira Aurelio \\ ORCID: https://orcid.org/0000-0003-2378-2079 \\ University of West Paulista, Brazil \\ E-mail: samucaurelio@gmail.com \\ Felipe Viegas Rodrigues \\ ORCID: https://orcid.org/0000-0002-1073-867X \\ University of West Paulista, Brazil \\ E-mail: rodrigues.fv@gmail.com
}

\begin{abstract}
Generalized Anxiety Disorder (GAD) affects individuals of all ages, causing physical and cognitive impairment, thus reducing their quality of life. The evaluation of the cognitive capacity of patients with GAD is an important tool when trying to understand the damages that this disorder brings to the individual. Therefore, the present study aimed to understand if there are losses or alterations in cognitive functions, mainly executive ones of these individuals. Twentyone subjects, both men and women, underwent a 2-back test to assess working memory performance and a Stroop Task to assess inhibitory control, comprising a TAG Group $(n=11)$ and a Control Group $(n=10)$. The patients were selected from ambulatory care at a tertiary hospital in the Western São Paulo. The results showed important differences in the performance of patients with GAD, who exhibited equivalent reaction time (RT) performance in the 2-back test, but with a greater number of errors. At the Stroop task they are consistently slower than the Control Group, for the equivalent number of errors. Taken together, these data point to significant prejudice in GAD, even within a limited sample of subjects.
\end{abstract}

Keywords: Executive function; Psychophysics; Stroop task; Anxiety disorders.

\section{Resumo}

O Transtorno de Ansiedade Generalizada (TAG) afeta indivíduos de todas as idades, causando prejuízos físicos e cognitivos, diminuindo assim a qualidade de vida dos mesmos. A avaliação da capacidade cognitiva de pacientes com TAG se mostra uma importante ferramenta quando tentamos compreender os prejuízos que esse transtorno traz ao indivíduo. Desse modo, o presente estudo teve como objetivo compreender se existem prejuízos ou alterações em funções cognitivas, principalmente executivas desses indivíduos. Vinte e um sujeitos, homens e mulheres, realizaram um teste 2-back para avaliação do desempenho de memória operacional e um teste de Stroop para avaliar o controle inibitório, perfazendo um Grupo TAG $(n=11)$ e um Grupo Controle $(n=10)$. Os pacientes foram selecionados a partir do atendimento ambulatorial de um hospital terciário do Oeste Paulista. Os resultados mostraram diferenças importantes no desempenho de pacientes com TAG, que exibiram desempenho equivalente de tempo de reação (RT) no teste 2-back, porém com maior número de erros. No teste de Stroop eles são consistentemente mais lentos do que o Grupo Controle, para número equivalente de erros. No conjunto, estes dados apontam para prejuízos importantes no TAG, mesmo numa amostra limitada de sujeitos.

Palavras-chave: Função executiva; Psicofísica; Teste de stroop; Transtornos de ansiedade.

\section{Resumen}

El Trastorno de Ansiedad Generalizada (TAG) afecta a individuos de todas las edades, provocando deterioro físico y cognitivo, reduciendo así su calidad de vida. La evaluación de la capacidad cognitiva de los pacientes con TAG es una 
herramienta importante a la hora de intentar comprender los daños que este trastorno trae al individuo. Por lo tanto, el presente estudio tuvo como objetivo comprender si existen pérdidas o alteraciones en las funciones cognitivas, principalmente ejecutivas de estos individuos. Veintiún sujetos, tanto hombres como mujeres, se sometieron a una prueba de 2 espaldas para evaluar el rendimiento de la memoria de trabajo y una tarea Stroop para evaluar el control inhibitorio, que comprende un grupo TAG $(n=11)$ y un grupo de control $(n=10)$. Los pacientes fueron seleccionados para la atención ambulatoria en un hospital de tercer nivel en el Oeste de São Paulo. Los resultados mostraron diferencias importantes en el desempeño de los pacientes con TAG, quienes exhibieron un desempeño equivalente en tiempo de reacción (TR) en el test de 2 espaldas, pero con mayor número de errores. En la tarea de Stroop son consistentemente más lentos que el Grupo de Control, por el número equivalente de errores. En conjunto, estos datos apuntan a un prejuicio significativo en GAD, incluso dentro de una muestra limitada de sujetos.

Palabras clave: Función ejecutiva; Psicofísica; Test de stroop; Trastornos de ansiedad.

\section{Introduction}

Anxiety is considered a normal state of the mind when people are exposed to a situation of apprehension or fear provoked by the anticipation of unpleasant and dangerous outcomes. It may, however, be pathological as in Generalized Anxiety Disorder (GAD) marked by excessive anxiety and worry (Angelotti, 2007).

Impairment of executive functions (EF) have been shown to be associated with several cognitive disorders resulting from lesions, neurological dysfunction, and psychiatric disorders, compromising the individual social, intellectual and affective faculties, thus, preventing them from acting efficiently in their own routine. Dias (2014) argues that EFs are a set of high order cognitive abilities that perform the coordination of adaptive responses to new or complex situations. Such skills include inhibiting irrelevant elements, selecting, integrating, and manipulating relevant information, the intention and execution of an action, cognitive and behavioral flexibility, and attitude self-monitoring (Chan et al., 2008).

According to Ylikoski and Hänninen (2003), EF could be divided into four subcomponents: the first one is related to volition and is described by anticipation, motivation, and intentional behaviour towards action. The second one, to planning, including conceptualization, decision making and evolving a framework or goal for carrying out a plan. Third one, leans towards purposive action, and is important for programming of activities, maintaining, integrating, and switching sequences of behaviour and for mental flexibility and memory. Last subcomponent, monitoring, deals with controlling effective performance, regulates the qualitative aspects of behaviour and feedback utilization. The authors defend that knowing the essential subcomponents and concepts of EFs is important for evaluating the best methodology of assessment of the prefrontal function.

Mesulam (2000) and Royall et al. (2002) presume that individuals with GAD, EFs may have errors of interpretation of the environmental stimuli, difficulties in self-monitoring processes, leading to intense, disproportional and disadaptive responses. In anxiety disorders, the presence of deficits in inhibitory control leads to a lack of cognitive flexibility, therewith, poor ability to change or alter actions, lack of filtering and selection of information, and lack of planning, or in other words, little capacity to establish a strategy to achieve a goal (Dias, 2014).

Indeed, Dias (2014) observed in adults, through a battery of neuropsychological tests, that the deficit of inhibitory control leads to motor impulsivity, difficulty in inhibiting the repetition of ideas, mental inertia and confusing decision making. Thus, subjects presented the non-suppression of automatic responses when the context is altered, affecting their adaptive capacity, and generating an error in their response. It was still possible to observe the difficulty of motor inhibition, restrain incoherent responses and observe impulsive behaviors.

Menon (2011) argues the neural networks can be divided into three core neurocognitive networks, that reflects strong coupling of spontaneous fluctuations in ongoing activity. The first, metabolically active when the subject rests - introspective and entertained with autobiographical thoughts and therefore not engaged in cognitive or propositional demands - is the default mode network (DMN), which involves the medial prefrontal cortex (MPFC) angular gyrus (AG) and posterior cingulate cortex 
(PCC). The second is the central executive network (CEN), which is activated by propositive tasks (task-positive), therefore, implied in executive functions, which involves working memory and sustained attention (goal oriented) and anchors itself in the frontoparietal system, such as dorsolateral prefrontal cortex (DLPFC), posterior prefrontal cortex (PPC) and medial temporal area (MT). The third network is responsible for the modulation of stimulus-driven attention and the harmonious alternation between DMN and CEN: the salience network (SN), which emerges from the fronto-insular and limbic activity, that is, the anterior insula in relation to ventrolateral prefrontal cortex (VLPFC) and anterior cingulate cortex (ACC), with also inputs from subcortical structures such as amygdala, ventral striatum, and substantia nigra.

It is in the circuitry of the ACC portion that adaptive attentional control and fine problem-solving are processed, while the processing of negative valence events occurs subcortically by the Amygdala and the generation of negative emotional responses, such as sadness, in the ventral portion of the ACC.

The Stroop task is a classic task used to evaluate inhibitory control and EF, composed of two tasks: one of word reading and one of color naming. The word reading task gives an indication of reading fluency. The fact that there may be incongruity between the name of the color and the very color in which it is represented in screen causes an interference effect of the color's naming, this interference is called the Stroop effect. The Stroop effect is, thereby, a phenomenon of delay in naming the color of a word, if this word is disposing of a different color name than the one to be named, for example, asking to read the word "red" when it is written in green (Stroop, 1935).

This type of test is used to measure executive control and concentration, or to screen for cognitive dysfunction. For the results to be valid, they must ensure that the person recognizes the colors and knows how to successfully name them. It's also important to find out what their level of education is, as the test can affect the readiness and fluency of reading (Washburn, 2016), or ensure homogeneity of study groups.

It is possible that changes also exist in processes involving working memory and attention of individuals with GAD, both important for EF. According to Helene and Xavier (2003), the association involving memory and attention allows finding a wide diversity of phenomena usually investigated in attention studies, as well as generating testable predictions about the performance of people in tests that involve attention.

Attention is a selection mechanism that, by means of choice and prioritization, performs processing of information. It is an integral part of the working memory, which performs the temporary archiving and information management, important for various cognitive functions. It is possible to generate predictions of future situations, to select the information for later action and the development of intentionality (desired results can be predicted), which gives the human being an adaptive advantage (Helene and Xavier, 2003).

The n-back test evaluates the number of items that can be archived temporarily, thus being a great tool for measuring working memory capacity. It consists of a random presentation of verbal or nonverbal stimuli, and the presentation of letters is the most common protocol. It must be understood that " $n$ " is an integer that can range from 0 to 4 . The participant should react to the stimulus presented on screen and always indicate (with the press of a button) if the stimulus was presented at an anterior position ( $n=1)$, two positions ( $n=2)$ and so on. If it was not, another button press should be made. As the value of " $n$ " increases, the difficulty also becomes greater. Thus, with this test, real-time monitoring, updating and manipulation of the information being stored is possible (Owen et al., 2005).

Yaple et al., (2019) argue that the n-back test is the most common measure of working memory performance. The authors showed that the neural regions active during the execution of the n-back test change over time. While young people have more prominent DLPFC activations, this functional finding decreases proportionally to age (specifically in adults and the elderly). Consistent across all age groups, the authors found activity in ACC, although its role is interpreted as conflict solver, and in the parietal cortex, in regions involved in the orientation of attention. The authors also verified activations in insula, 
claustrum and cerebellum in all groups, data usually not reported in relation to working memory.

With so many regions involved in the functioning of executive processes, or simply the EF, and with the amygdala responsible for part of the modulations performed in these circuits, it is very probable that subjects with GAD, with their characteristic functional alterations of amygdala, have important changes in EF. To efficiently measure the magnitude of these changes is an important task in these patients' therapy, which can serve as a therapeutic and prognostic guidance in their treatment.

In the present study we examined the possible changes in the EF of patients with GAD. We posed a simple question: could the functional changes imposed by the anxiety syndrome impair working memory efficiency and inhibitory control? We addressed this by evaluating the performance of patients with GAD in the 2-back test, important in the manipulation of data in working memory and tested the inhibitory control of the patients through the Stroop task.

\section{Methodology}

\subsection{Sample}

The research and all the procedures performed with the volunteers were approved by the National Research Ethics Committee under CAAE number 89236818.7.0000.5515. All participants completed a Free and Informed Consent Term before beginning the tests proposed in the survey and being aware of the possibility of withdrawal at any time.

Twenty-nine subjects, men and women, all patients from a tertiary hospital in western São Paulo participated in the study. Education was monitored among participants. Those who composed the GAD group $(n=13)$ were indicated by the psychiatrist responsible for the anxiety ambulatory and were already being treated or were new outpatient cases. The Control group ( $\mathrm{n}=16)$ was established from other hospital (non-psychiatric) patients or companions. We excluded: (1) one subject from the Anxiety Group and two controls because they gave up the tests, (2) a patient who had a primary diagnosis of obsessive-compulsive disorder (OCD) and not GAD, and (3) four control subjects who responded incorrectly to the tests. Total final participants included in the analysis were Control group $(n=10)$ and GAD group $(n=11)$. Given the low number of final participants in the groups, it was not possible to make analyzes regarding sex.

\subsection{Apparatus}

The test protocols were elaborated with the software PsychoPy (Peirce et al., 2019) and executed on a computer running Windows ${ }^{\circledR} 1064$ bit, with a 17" screen with 1080p resolution at 60hz. The tests were performed at the hospital itself, due to the ease of access to the patients. One of the ambulatory rooms, climatized, was reserved for the experiments and the illumination was attenuated to improve the contrast on the screen. The subjects were seated comfortably in front of the computer, always centered in relation to the screen.

\subsection{2-back test}

The working memory was evaluated by means of the 2-back test (Owen et al., 2005). The test consisted of the presentation of uppercase letters on the computer screen, in random sequence, one every three seconds. The participant was instructed to compare the present letter with the previous ones. If the second to last letter (penultimate) were the same as the current one, he/she should press the "M" button with the right hand, and if the penultimate letter were different, he/she should press the "Z" button with the left hand. It should be noted that the performance of this task required the volunteer to keep in its working memory a small list of the last letters presented, in order to allow its comparison with the on-screen letter. The stimulus remained on the screen until the subject's response, limited to a maximum of $2000 \mathrm{~ms}$. 
A single test session was performed with 200 attempts divided into nine blocks of twenty attempts each. The first block served the participants as training, and they only started the valid blocks after resolving all doubts regarding the experiment. Altogether, there were 160 attempts considered by the subject. The interval between the blocks was free and the subjects returned to the experiment as soon as they were prepared.

The reaction times for the correct responses of each participant in the twenty attempts of each of the nine valid blocks allowed calculating the median of the reaction times per block. In the analysis involving groups, the mean of these medians was calculated. The median was chosen to express the performance in the block, because this measure is less subject to the influence of sporadic extreme scores, representing in a more reliable manner the participant's performance. To evaluate the accuracy of the response, the percentage of errors was calculated.

\subsection{Stroop Task}

The attention was assessed by a variation of the Stroop task (Stroop, 1935) and presented following the 2-back test, after a free interval that allowed the experimenter to explain the test to the participant.

The test consisted of nine blocks of twenty-four attempts each and the participants were instructed to respond to the congruence between the color of the words (always color names) and the word that appeared on the screen. Words were presented in a congruent condition (written in the same color they name) and incongruent condition (written with different color than the one they name). Performance at this task required the participant to inhibit normal reading automaticity. The fastest color naming response to the words that are congruent is already well established for the Stroop task (see Washburn, 2016). The participants should press the " $M$ " button if the answer was congruent and the " $Z$ " button if the answer was incongruent. The first block was again considered a training block and discarded in the subsequent analysis of data.

The reaction times of each subject, for the correct attempts, considering congruent and incongruent attempts, allowed to calculate the median of the reaction times per block. In the analysis involving groups, the mean of these medians was calculated. To evaluate the accuracy of the response, the percentage of errors was calculated also.

\subsection{Data analysis}

Analysis of variance for repeated measurements (ANOVA) was used to compare the mean reaction times and the mean percentage of errors in the 2-back test, having group (Control vs. GAD) as between-subjects factors and blocks of attempts (in a total of eight blocks) as within-subjects factors.

In the Stroop task, another ANOVA was used to compare reaction times, having group (Control vs. GAD) as between-subjects factors and blocks of attempts (in a total of eight blocks) and condition (congruent vs incongruent) as withinsubjects factors. The charts were all made on python with the use of the Matplotlib library (Hunter, 2007).

Interpretation of the results were made based on a more parsimonious understanding of statistical significance (Amrhein \& Greenland Mcshane, 2019, Krueger \& Heck 2019). 


\section{Results}

\subsection{Reaction time in the 2-back test}

The ANOVA for the reaction times in the 2-back test showed significant effect for block $(\mathrm{F} 7.133=3.199, \mathrm{p}=0.004)$, indicating that the participants did learn the task and improved performance along the blocks (Figure 1).

Figure 1. Reaction times along the blocks in the 2-back test for the Control and GAD groups. Bars represent standard error of the mean (SEM). Group ANOVA: $\mathrm{p}=0,795$.

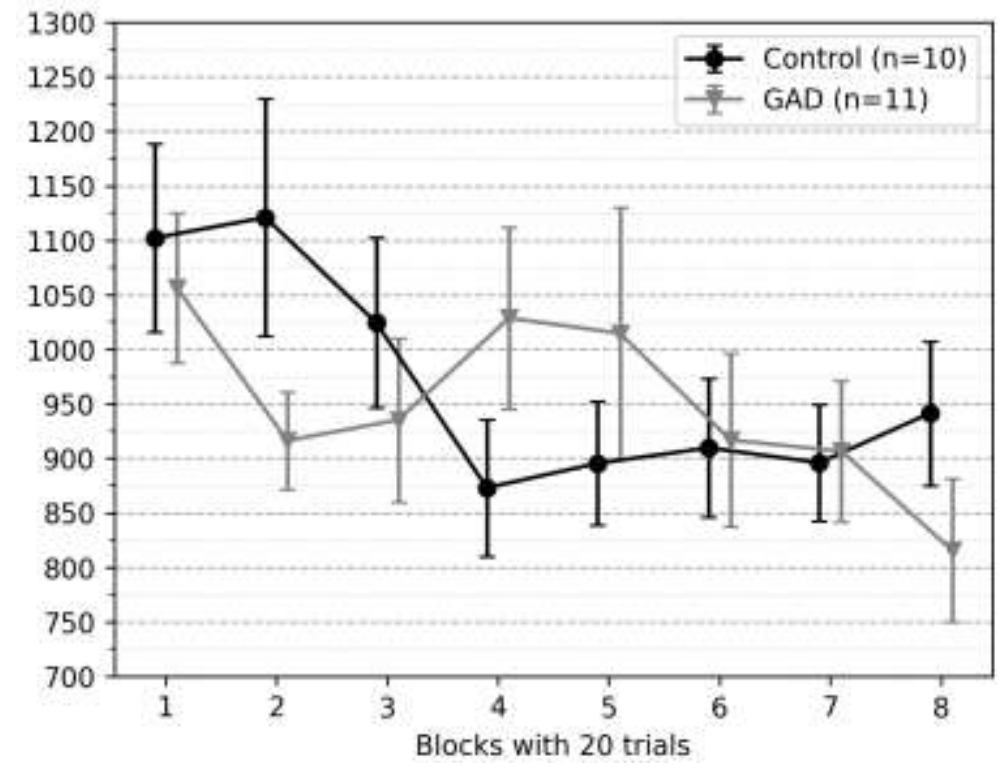

Source: Authors.

ANOVA also showed a significant effect for the interaction between block and group $\left(\mathrm{F}_{7.133}=2.695, \mathrm{p}=0.012\right)$. The analysis of Figure 1 allows us to observe that the control and GAD patients perform differently along the test. Considering the ups and downs of the reaction times of each group, ANOVA showed no significant differences between groups $\left(\mathrm{F}_{1.19}=0.069\right.$, $\mathrm{p}=0,795)$.

\subsection{Percentage of errors in the 2-back test}

The ANOVA for the percentage of errors in the 2-back test showed significant effect for block $\left(\mathrm{F}_{7.133}=5.426 \mathrm{p}<0.001\right)$, indicating again that the participants learned the task and improved performance along the test blocks (Figure 2). ANOVA also showed a significant difference between groups $\left(\mathrm{F}_{1.19}=3.576, \mathrm{p}=0,074\right)$.

The analysis of Figure 2 shows that the control group misses less than the GAD group. It could be also supposed that the shortest reaction time of the GAD group was achieved at the cost of the highest number of errors, at least in blocks two and three. 
Figure 2. Percentage of errors in the 2-back test for the Control and GAD groups. Bars represent SEM. Group ANOVA: $\mathrm{p}=0,074$.

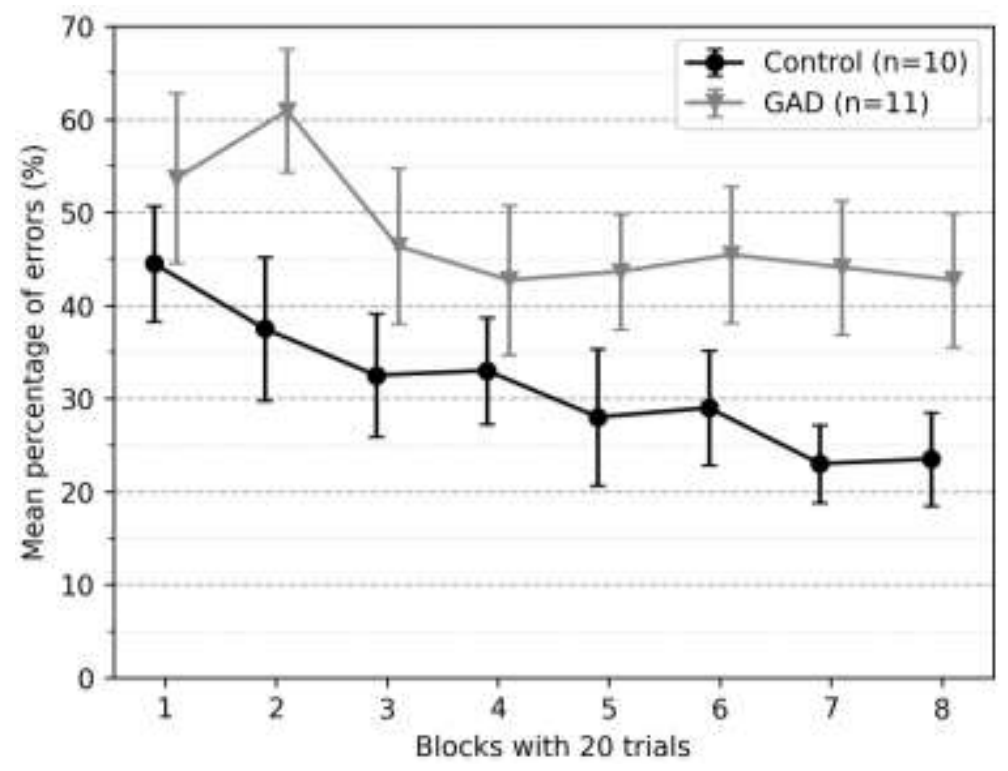

Source: Authors.

\subsection{Reaction times in the stroop task}

The ANOVA for the reaction times in the Stroop task showed a significant effect for congruence $\left(F_{1.19}=11.754\right.$, $\mathrm{p}=0.003$ ), indicating that the subjects responded faster to a congruent condition, in relation to incongruent ones (Figure 3).

Figure 3. Reaction times in the Stroop task for the Control and GAD groups for the attempts with congruent and incongruent colors. Bars represent SEM. Group ANOVA: $\mathrm{p}=0,107$.

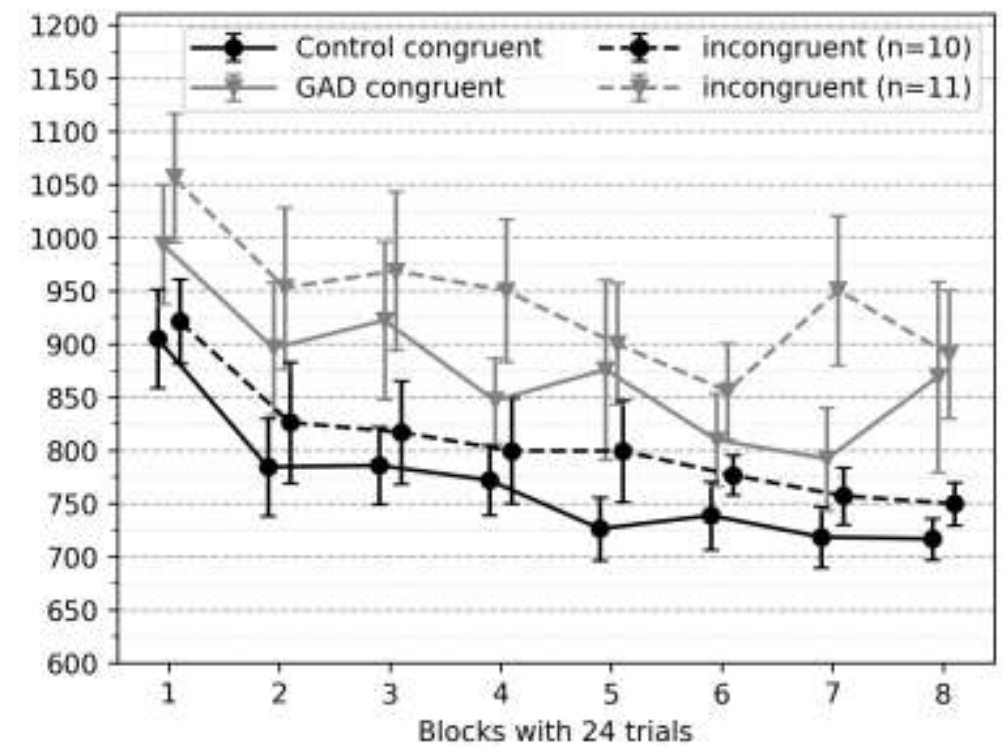

Source: Authors.

ANOVA also showed significant differences for block $\left(\mathrm{F}_{7.133}=7.606, \mathrm{p}<0.001\right)$ since the subjects respond faster as they learn the task in progress (Figure 3). All other interactions are non-significant. Comparison between groups suggests 
differences $\left(\mathrm{F}_{1.19}=2.971, \mathrm{p}=0,107\right)$, and Figure 3 in fact shows that the control group was faster to respond to congruent and incongruent stimuli in the Stroop task.

\subsection{Percentage of errors in the Stroop task}

The ANOVA for the percentage of errors in the Stroop task reveals significant differences for block $\left(\mathrm{F}_{7.133}=2.254\right.$, $\mathrm{p}=0,034$ ), not confirmed by post hoc test, however. Moreover, there were no significant differences for congruence $\left(\mathrm{F}_{7.133}=2.422, \mathrm{p}=0,136\right)$, and any interactions (Figure 4$)$.

Figure 4. Percentage of errors in the Stroop task for the Control and GAD groups for the attempts with congruent and incongruent colors. Bars represent SEM. Group ANOVA: $\mathrm{p}=0,243$.

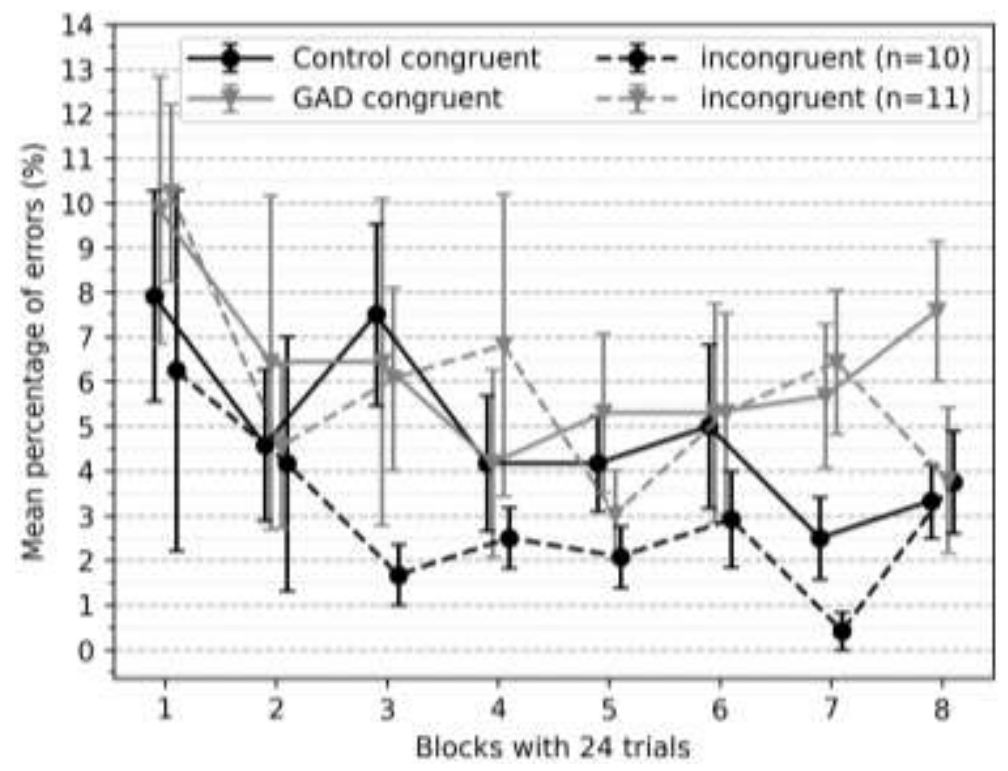

Source: Authors.

ANOVA also revealed no difference between groups $\left(\mathrm{F}_{1.19}=1.454, \mathrm{p}=0,243\right)$. The analysis of Figure 4 allows observation that the average error rate is low (less than $8 \%$ from block 2 ).

\section{Discussion}

The present dataset points to important differences in the performance of patients with Generalized Anxiety Disorder (GAD) in two tasks that use Executive Functions (EFs): a working memory test (2-back test) and an attention and inhibitory control test (Stroop task). The GAD Group, although they have equivalent reaction time (RT) performance in the 2-back test, seem to have achieved this result at the cost of a greater number of errors. In the Stroop task they are consistently slower than the Control Group, for an equivalent number of errors.

According to Dias (2014) individuals with GAD have impulsive behaviors, which impair their ability to inhibit incoherent responses, in a mechanism that when the context is altered, still cannot eliminate an automatic response, thus impairing their adaptive capacity. The errors increase, besides the same reaction times for the GAD group, is evidence of this. It is interesting how the curves for RT and errors seem to evolve in exactly the opposite way, except in the last block, when the GAD group has improved both the RT and the number of errors. Still, they made more errors than the Control Group.

This impairment is not uncommon for anxious disorders: hyperactivity of the amygdala and even hypertrophy have a positive correlation in the pediatric population with GAD, as also observed in adolescents: excessive reactivity of the right 
amygdala, in contrast to right hypoactivity of the VLPFC, suggests loss of top-down inhibition as a possible underlying mechanism (Martin et al., 2010).

Maslowoski et al. (2010) showed angry faces (a common emotional-aversive stimulus) to forteen youths with GAD and ten age and gender matched healthy peers. GAD subjects were medicated or undergoing cognitive behavioral therapy $(\mathrm{CBT})$. Results showed that both treatments were able to increase right VLPFC activation in response to angry faces, which, authors argue, indicates that the VLPFC may facilitate effective responses to underlying neural correlates of anxiety in other brain regions, such as the amygdala.

Although hyperactivity and hypertrophy of the amygdala have not been consistently reported in the adult population with GAD, Etkin et al., (2010) demonstrated that these subjects, when exposed to a conflicting emotional task, had deficits both in the activation of regions relevant to emotional control - failure of top-down control of the pregenual cingulate cortex (pACC) - as well as differences in connectivity between the pACC and the amygdala.

As an adaptive mechanism, since the simultaneous hyperactivity of the amygdala with hyperactivity of the DLPFC and posterior parietal cortex (PPC) cortices was not found in the control groups, their studies also reveal the compensatory involvement of the frontoparietal system or central executive network in those affected by GAD, representing additional attempts of circuits responsible for inhibitory control to compensate for bottom-up hyperactivity (Etkin et al., 2009).

The dysfunctional impairment of the GAD in EF could, therefore, undermine the attentional system that involves downward control (top-down), in favor of ascending processing (bottom-up). As observed in our results, the GAD patients seem to favour the faster response, to the detriment of the correct one. Interestingly, this strategy error was applied to the 2 back test, but not to the Stroop task, possibly because the overload in decision-making systems is higher in this second test than it is in the first one, so that the necessity of blocking the automatism of a response works even in the subjects with GAD for the Stroop task, but not on the 2-back test, which further exacerbates the impulsiveness in GAD.

In fact, in the Stroop task the GAD group managed to balance the number of errors, indicating that they were successfully inhibiting the automaticity of the word reading to present correct responses to the incongruent trials. This process, however, was considerably slower on them, than was on the Control Group. First, it may be interesting to reaffirm that colorword congruence assists in responding to the Stroop task, so that consistently most participants respond more quickly to congruent trials in relation to incongruent trials. Besides that, the functional damage of GAD patients become more evident: the RTs of the Control Group in the incongruent trials are as fast as (and probably faster than) the congruent GAD group trials.

These differences may be aligned with the hyperactivity of the executive circuits as verified by Etkin et al. (2010), as a compensatory mechanism for correct execution of tasks. When the GAD group can exercise top-down mechanisms, they do so with greater executive effort and longer RTs. According to the classification of Ylikoski and Hänninen (2003), the prejudice would be in the third sub-component of the EF, since there is difficulty in promoting attention control and inhibition. The authors even advocate that the Stroop task is one of the tasks of choice to test this third subcomponent.

According to the findings of MacDonald et al. (2000) - that argue the Stroop Task can activate differentially the DLPFC and the anterior ACC - we can suppose that there are functional differences in the ACC of subjects with GAD, since there is an increase in the RT in relation to the Control Group. That is, since there is no increase in the number of errors and there is Stroop effect (difference between Congruent and Incongruent), the subjects did the task very adequately, however, with more processing of information needed to solve the conflict generated in the test Stroop.

Extrapolating the findings of MacDonald et al. (2000), it is likely that DLPFC is also dysfunctional in GAD, since there is also an impairment in the 2-back test. This dysfunction, however, does not interfere with RT (because there is no conflict resolution required), but only with the number of errors given the limitation of resources in GAD and the characteristic impulsiveness of anxiety disorders, as already demonstrated by Dias (2014). 
It is noteworthy that the choice of the 2-back task was bold. The test was considered quite difficult by all participants in the experiment, with considerably higher error rates than the Stroop task. This overload on working memory circuits, however, scaled considerably more on GAD patients than controls. Along with all the other dysfunctions already pointed out, this evidence suggests that GAD patients have discreet losses that probably impact everyday life.

\section{Final Thoughts}

Taken together, these data point out to significant losses in generalized anxiety disorder, even on the limited sample of the present work. Therefore, the need for a more careful look at this population is highlighted, regarding drug treatment and stabilization, and recognition of functional limitations in a wide range of tasks that involve EF.

Future work should focus on aspects of the development of the Amygdala and the possibilities of developing preventive strategies for hypertrophy and hyperactivity in this nucleus. Also, on the investigation of EF in clinically stabilized patients, in order to understand whether the clinical improvement of these subjects extends also to cognitive functions.

\section{References}

Amrhein, V., Greenland, S., \& Mcshane, B. (2019). Scientists rise up against statistical significance. Nature. 567:305-307. https://doi.org/10.1038/d41586019-00857-9.

Angelotti, G. (2007). Terapia Cognitivo Comportamental para os Transtornos de Ansiedade. Casa Psi Livraria, Editora e Gráfica LTDA.

Barlow, D. H., \& Bruce C. F. (1998). The Development of Anxiety: The Role of Control in the Early Environment. Psychological Bulletin. 124(1), 3-21. https://doi.org/10.1037/0033-2909.124.1.3.

Castillo, A. R., Recondo, R., Asbahr, F. R., \& Manfro, G. G. (2000). Transtornos de ansiedade. Revista Brasileira de Psiquiatria. 22(2), 20-

23. https://doi.org/10.1590/S1516-44462000000600006.

Chan, R. C. K., Shum, D., Toulopoulou, T., \& Chen, E. Y. H. (2008). Assessment of executive functions: Review of instruments and identification of critical issues. Archives of Clinical Neuropsychology, 23, 201 - 216. https://doi.org/10.1016/j.acn.2007.08.010.

Dias, C. M. (2014). Avaliação Neuropsicológica das Funções Executivas em um Adulto com Sintomas de Ansiedade. Monografia (Curso de Especialização em Neuropsicologia). Instituto de Psicologia da Universidade Federal do Rio Grande do Sul. Porto Alegre.

Diamond, A. (2013). Executive functions. Annual Review of Psychology, 64, 68 - 135. https://doi.org/10.1146/annurev-psych-113011-143750.

Goldberg, E. (2002) O cérebro executivo: Lobos frontais e a mente civilizada. Imago. 139 - 150.

Etkin, A., Prater, K. E., Hoeft, F., Menon, V. \& Schatzberg, A. F. (2010). Failure of Anterior Cingulate Activation and Connectivity with the Amygdala During Implicit Regulation of Emotional Processing in Generalized Anxiety Disorder. Am J Psychiatry. $167(5)$, 545 - 554. https://doi.org/10.1176/appi.ajp.2009.09070931.

Etkin, A., Prater, K. E., Schatzberg, A. F., Menon, V. \& Greicius, M. D. (2009). Disrupted amygdalar subregion functional connectivity and evidence of a compensatory network in generalized anxiety disorder. Arch Gen Psychiatry. 12(66), 1361 - 1372. https://doi.org/10.1001/archgenpsychiatry.2009.104.

Helene, A. F., \& Xavier, G. F. (2003). A construção da atenção a partir da memória. Revista Brasileira de Psiquiatria. 25(2), 12 - 20. https://doi.org/10.1590/S1516-44462003000600004.

Hunter, J. D. (2007). Matplotlib: A 2D Graphics Environment. Computing in Science \& Engineering. 9(3):90-95. https://doi.org/10.1109/MCSE.2007.55.

Kaplan, H. I., \& Sadock B. J. (1999). Tratado de Psiquiatria. (6a ed.). ARTMED.

Krueger, J. I., \& Heck, P. R. (2019). Putting the P-Value in its Place. The American Statistician 73(sup1):122-128. https://doi.org/10.1080/00031305.2018.1470033

Macdonald et al. (2000). Dissociating the Role of the Dorsolateral Prefrontal and Anterior Cingulate Cortex in Cognitive Control. Science 288(5472): 18351838. https://doi.org/10.1126/science.288.5472.1835

Machado, M. B. et al. (2016). Prevalência de transtornos ansiosos e algumas comorbidades em idosos: um estudo de base populacional. J Bras Psiquiatr. 65(1):28-35. https://doi.org/10.1590/0047-2085000000100.

Martin, E. I., Ressler, K. J., Binder, E., \& Nemeroff, C. B. (2010). The Neurobiology of Anxiety Disorders: Brain Imaging, Genetics, and Psychoneuroendocrinology. Clinics in Laboratory Medicine. 30(4). 865 - 891. https://dx.doi.org/10.1016\%2Fj.psc.2009.05.004.

Maslowsky, J. et al. (2010). A preliminary investigation of neural correlates of treatment in adolescents with generalized anxiety disorder. J Child Adolesc Psychopharmacol. 20(2).105 - 111. https://doi.org/10.1089/cap.2009.0049. 
Research, Society and Development, v. 11, n. 2, e9311225603, 2022

(CC BY 4.0) | ISSN 2525-3409 | DOI: http://dx.doi.org/10.33448/rsd-v11i2.25603

Menon, V. (2011). Large-scale brain networks and psychopathology: a unifying triple network model. Trends Cogn Sci. 15(10), 483 - 504. https://doi.org/10.1016/j.tics.2011.08.003.

Mesulam, M. M. (2000). Behavioral neuroanatomy: Large-scale networks, association cortex, frontal syndromes, the limbic system, and hemispheric specializations. In M. M. Mesulam (Org.), Principles of behavioral and cognitive neurology. New York: Oxford University Press. 119 - 150.

Owen, A. M., Mcmillan, K. M., Laird, A. R., \& Bullmore, E. (2005). N-Back Working Memory Paradigm: A Meta-Analysis of Normative Functional Neuroimaging Studies. Human Brain Mapping. 25:46-59. https://doi.org/10.1002/hbm.20131.

Royall, D. R., Lauterbach, E. C., Cummings, J. L., Reeve, A., Rummans, T. A., Kaufer, D. I., et al. (2002). Executive control function: A review of its promise and challenges for clinical research. A report from the Committee on Research of the American Neuropsychiatric Associations. Journal of Neuropsychiatry Clinical Neuroscience, 14, 377- 405. https://doi.org/10.1176/jnp.14.4.377.

Silva, A. B. B. (2017). Mentes Ansiosas: O medo e a ansiedade nossos de cada dia. (2a ed.). Editora Globo S.A.

Stroop, J. R. (1935). Studies of interference in serial verbal reactions. Journal of Experimental Psychology. 18(6):643-662. https://psycnet.apa.org/doi/10.1037/h0054651.

Washburn, D. A. (2016). The Stroop effect at 80: The competition between stimulus control and cognitive control. J Experim Analysis of Behavior. Jan, 105(1):3-13. https://doi.org/10.1002/jeab.194.

Yaple, Z. A., Stevens, W. D., \& Arsalidou, M. (2019). Meta-analyses of the n-back working memory task: fMRI evidence of age-related changes in prefrontal cortex involvement across the adult lifespan. NeuroImage. v. 196. p. 16-31. https://doi.org/10.1016/j.neuroimage.2019.03.074.

Ylikoski, R., \& Hanninan, T. (2003). Assessment of executive function in clinical trials. International psychogeriatrics, 15 , 219 - 224. https://doi.org/10.1017/s1041610203009232. 